OPEN ACCESS

Edited by:

Amir Shmuel,

McGill University, Canada

Reviewed by:

Galit Pelled,

Johns Hopkins School of Medicine,

USA

Kai-Hsiang Chuang,

Singapore Bioimaging Consortium,

Singapore

*Correspondence:

Luciene Covolan,

Rua Botucatu, $8625^{\circ}$ andar, São

Paulo, SP 04023-062, Brazil

Icovolan@unifesp.br

${ }^{\dagger}$ Both are first authors.

Specialty section:

This article was submitted to Brain Imaging Methods, a section of the

journal Frontiers in Neurology

Received: 29 December 2014

Accepted: 29 June 2015

Published: 10 July 2015

Citation:

Malheiros JM, Paiva FF, Longo BM,

Hamani C and Covolan L (2015)

Manganese-enhanced MRI: biological applications in neuroscience.

Front. Neurol. 6:161.

doi: 10.3389/fneur.2015.00161

\title{
Manganese-enhanced MRI: biological applications in neuroscience
}

\section{Jackeline Moraes Malheiros ${ }^{1,2 \dagger}$, Fernando Fernandes Paiva ${ }^{2 \dagger}$, Beatriz Monteiro Longo ${ }^{1}$, Clement Hamani ${ }^{1,3,4}$ and Luciene Covolan ${ }^{1 *}$}

${ }^{1}$ Department of Physiology, Universidade Federal de São Paulo - UNIFESP, São Paulo, Brazil, ${ }^{2}$ Centro de Imagens e Espectroscopia In vivo por Ressonância Magnética, Institute of Physics of São Carlos, Universidade de São Paulo, São Carlos, Brazil, ${ }^{3}$ Research Imaging Centre, Centre for Addiction and Mental Health, Toronto, ON, Canada, ${ }^{4}$ Centre for Addiction and Mental Health, Campbell Family Mental Health Research Institute, Toronto, ON, Canada

Magnetic resonance imaging (MRI) is an excellent non-invasive tool to investigate biological systems. The administration of the paramagnetic divalent ion manganese $\left(\mathrm{Mn}^{2+}\right)$ enhances MRI contrast in vivo. Due to similarities between $\mathrm{Mn}^{2+}$ and calcium $\left(\mathrm{Ca}^{2+}\right)$, the premise of manganese-enhanced MRI (MEMRI) is that the former may enter neurons and other excitable cells through voltage-gated $\mathrm{Ca}^{2+}$ channels. As such, MEMRI has been used to trace neuronal pathways, define morphological boundaries, and study connectivity in morphological and functional imaging studies. In this article, we provide a brief overview of MEMRI and discuss recently published data to illustrate the usefulness of this method, particularly in animal models.

Keywords: manganese, tracing method, epilepsy, nociception, anatomy, MRI

\section{Introduction}

Magnetic resonance imaging (MRI) is an excellent non-invasive tool for providing anatomical information of biological systems (1-6) due to its unique soft tissue contrast and relatively high-spatial resolution.

With a large variety of MRI applications being proposed, great effort has been made to develop contrast agents that may add physiological and/or molecular information to anatomical images (7). Along this line, the potential use of the paramagnetic manganese ion $\left(\mathrm{Mn}^{2+}\right)$, which induces a strong reduction in both longitudinal $\left(\mathrm{T}_{1}\right)$ and transversal $\left(\mathrm{T}_{2}\right)$ relaxation times, has been investigated (8). As $\mathrm{Mn}^{2+}$ has a high-chemical similarity with calcium $\left(\mathrm{Ca}^{2+}\right)$, it may enter neurons and other excitable cells through voltage-gated calcium channels and the $\mathrm{Na}^{+} / \mathrm{Ca}^{2+}$ exchanger (9).

Over the last decade, $\mathrm{Mn}^{2+}$ has been used as a contrast agent in various manganese-enhanced MRI (MEMRI) applications. These may be grouped in three major classes: neuronal tract tracing (10-14), morphological (15-18), and functional imaging (19-23). Typically, during neuronal tracttracing studies manganese is directly injected into a specific brain region (24-29). In other classes of applications, this ion is administered either systemically into the bloodstream (30-39) or directly into the cerebrospinal fluid (CSF) $(40,41)$.

Neuronal tract-tracing explores the transport of $\mathrm{Mn}^{2+}$ across synapses. In contrast, morphological and functional studies using MEMRI are dependent on local neuronal cell density, the permeability of the blood-brain barrier, and neuronal activation (42). In $\mathrm{Mn}^{2+}$-based functional MRI (fMRI), tissue contrast may be correlated with activity-dependent ion accumulation in excitable cells (43). As such, the contrast in MEMRI is more directly related to neural activity then fMRI blood 
oxygenation level dependent (BOLD) $(44,45)$. Another advantage is that $\mathrm{Mn}^{2+}$ uptake after systemic injections takes place over an extended period of time in awake and freely moving animals (46). As a result, only the MRI acquisition needs to be performed under anesthesia. This is another advantage of MEMRI over BOLD fMRI, which requires both stimuli and acquisition to be performed under sedation.

A major drawback of the use of $\mathrm{Mn}^{2+}$ is the toxic side effects observed at high concentrations (47-51). This is of concern as high- $\mathrm{Mn}^{2+}$ tissue levels are often required to enhance the contrast between structures (52-54). In fact, toxicity is one of the main limitations for the full development of $\mathrm{Mn}^{2+}$ as an MRI contrast agent for humans. Even in animal studies, there needs to be a compromise between avoiding toxicity and delivering adequate doses of manganese. The ultimate goal is to reduce systemic side effects while guaranteeing animal well-being and maximizing contrast and imaging quality $(8,17,55)$.

Several methodological developments have been recently proposed to improve MEMRI as a technique to study functional neural circuits and in vivo brain anatomy. In the present work, we provide a brief overview of MEMRI and illustrate the potential applications of this method in small animal models.

\section{Manganese-Enhanced MRI}

\section{Historical Perspective}

The first use of $\mathrm{Mn}^{2+}$ in nuclear magnetic resonance (NMR) coincides with the early days of this technique (56). Together with other ions, $\mathrm{Mn}^{2+}$ was employed in tests to measure the exchange rate of bulk water molecules with those in the first coordination sphere of paramagnetic ions (56). These findings played an important role in our understanding and optimization of water-exchange effects, a crucial step in the development of efficient $\mathrm{T}_{1}$-shortening MRI contrast agents (57-59). Later, $\mathrm{Mn}^{2+}$ was also used in experiments that enabled quantitative structural information to be obtained from biological molecules, which led to the development of techniques to determine protein structure using NMR (60).

$\mathrm{Mn}^{2+}$ has also been present since the earliest stages of MRI. Lauterbur (61) has used $\mathrm{MnSO}_{4}$ to change the longitudinal relaxation time of water and prove that relaxation times could affect signal intensity. This was an important step to demonstrate the feasibility of MRI, since, at that time, the technique was believed to be limited due to the small variations of water density in biological tissues (62). $\mathrm{Mn}^{2+}$ can then be considered as the first reported MRI contrast agent. Since then, it has contributed to our understanding of relaxation effects in biological systems (63). These are still considered to be helpful in establishing strategies to alter MRI contrast with exogenous agents and are extremely useful, not only in clinical practice but also in preclinical models $(64,65)$.

\section{Dosage and Toxicity}

The ion $\mathrm{Mn}^{2+}$ is essential for a normal development and cellular function. Disruptions in manganese homeostasis in humans are associated with neurological disorders, skin lesions, bone diseases, and among others (66-68). Chronic exposure to this heavy metal leads to manganism, a progressive neurodegenerative condition that resembles Parkinson's disease $(47,50,69,70)$. An acute overexposure to $\mathrm{Mn}^{2+}$, which happens when a high-systemic dose of contrast agents is administered to patients, may result in cardiac toxicity, hepatic failure, and even death $(48,49,71)$.

As the MEMRI contrast is proportional to the accumulation of tissue $\mathrm{Mn}^{2+}$ (52-54), the successful application of this technique depends on the delivery of appropriate ionic doses to the regions of interest. The most common way for delivering $\mathrm{Mn}^{2+}$ is through the injection of $\mathrm{MnCl}_{2}$ solutions (8). Depending on the application, $\mathrm{MnCl}_{2}$ can be delivered directly into the brain. This minimizes toxicity, since the exposure to lower doses of $\mathrm{Mn}^{2+}$ is restricted to the injection site and adjacent regions. Though focal toxicity may still occur (72), this approach has been successfully used in several studies of neuronal tract tracing (24-29).

For systemic injections targeting the brain, $\mathrm{MnCl}_{2}$ can be injected intravenously, intraperitoneally, or subcutaneously. So far, all have been widely used, as there is no strong evidence suggesting that one route is better or causes more toxicity than the others $(30,31,33-39)$. One of the major drawbacks of using systemic injections is that, prior to reaching the brain manganese reaches the liver, heart, and kidneys. This increases the risk of acute toxic effects, including cardiac, renal, and liver failure.

In the intact brain [i.e., without blood-brain barrier (BBB) breakdown], the time-course and distribution of $\mathrm{MnCl}_{2}$ varies across brain regions $(34,73)$. Under these circumstances, contrast enhancement seems to reach its equilibrium $24 \mathrm{~h}$ following administration. As this is particularly slow for brain activation studies, one strategy is to disrupt the $\mathrm{BBB}$ to accelerate uptake $(19,43,46)$. An alternative to avoid BBB disruption $(40,41)$ is to administer $\mathrm{MnCl}_{2}$ directly into the CSF. In this case, $\mathrm{Mn}^{2+}$ is uniformly supplied to the whole brain in a reasonable timescale for a variety of chronic functional activation studies.

The use of systemic fractionated injections (limited to small daily doses) was proposed as an alternative for delivering high doses of $\mathrm{Mn}^{2+}$ with fewer side effects in preclinical models (52, 53). A similar increase in contrast delivery with low toxicity has been observed with the use of subcutaneous mini-osmotic pumps (74). It is important to mention, however, that studies using these techniques were designed to demonstrate alternative ways of improving MRI contrast enhancement. Every attempt to use similar protocols should take into account reported changes in behavioral, neurochemical, electrophysiological, and histological signs of toxicity, especially when considering long-term effects (75-78).

\section{Routes of Administration}

In general, the route of delivery (i.e., systemic or intracerebral) is chosen based on the application. After the systemic administration, most $\mathrm{Mn}^{2+}$ likely reaches the brain through the blood-CSF barrier (79), enhancing the visualization of the cerebral cytoarchitecture and demarcating active brain regions. The focal cerebral administration enables mapping of neuronal tracts in the living brain, where $\mathrm{Mn}^{2+}$ is stored and transported along axonal tracts (75). As already mentioned, MEMRI applications can be grouped into three major classes: morphological (15-18), neuronal tract tracing $(6,10-14)$, and functional imaging (19-23). 
In contrast to gadolinium-based agents that are typically intravascular and remain in the cerebral vasculature, MEMRI contrast achieved after the systemic administration of $\mathrm{Mn}^{2+}$ comes from the brain parenchyma itself. $\mathrm{Mn}^{2+}$ may enter the brain basically through three different routes are as follows: (i) from the bloodstream via a fast transport system in the choroid plexus. Through this route, $\mathrm{Mn}^{2+}$ gets very rapidly into the CSF and brain $(80,81)$; (ii) from the nasal space through the olfactory nerve via olfactory epithelium $(25,82,83)$; (iii) from the bloodstream across the BBB at cerebral capillaries (84-87). In the intact brain, MEMRI signal enhancement following $\mathrm{Mn}^{2+}$ administration begins in the ventricles and periventricular regions prior to reaching more distant areas of brain parenchyma $(34,80,88)$.

Once in the brain, manganese may be transported along axons (89) or across synapses (26). The time-course and distribution of $\mathrm{MnCl}_{2}$ varies across brain regions $(34,73)$. Those with an initial poor access to manganese may be supplied over time by axonal transport from areas with a strong initial uptake (88). Contrast enhancement seems to reach its equilibrium $24 \mathrm{~h}$ following administration. Thereafter, manganese has an extremely slow clearance rate that can take up to 300 days, with a half-life of 51-74 days in different brain regions, as shown by autoradiography (90). MRI-based studies showed a reduced $\mathrm{Mn}^{2+}$ half-life of 5-12 days, but not of the same magnitude (54, 91, 92). Since the regional signal enhancement following manganese administration is proportional to the propensity of each brain region to uptake this metal, MEMRI is a powerful tool for visualizing brain architecture.

\section{Manganese Entrance into Excitable Cells}

Overall, $\mathrm{Mn}^{2+}$ presents a high-chemical similarity with calcium $\left(\mathrm{Ca}^{2+}\right)$, being handled in an analogous manner by many biological systems (93). This means that the $\mathrm{Mn}^{2+}$ can enter neurons and other excitable cells through calcium pathways, such as voltagegated calcium channels and the $\mathrm{Na}^{+} / \mathrm{Ca}^{2+}$ exchanger $(9,86)$. In addition, $\mathrm{Mn}^{2+}$ can bind to intracellular proteins and nucleic acids. Once in the cell, $\mathrm{Mn}^{2+}$ accumulates in the endoplasmic reticulum $(25,26)$, being subsequently packaged into vesicles and transported anterogradely in axonal tracts. Upon reaching the presynaptic membrane $(27,89)$, it is finally released and taken up by the next neuron $(25,27)$. This property, along with the fact that $\mathrm{Mn}^{2+}$ is MRI-detectable, has contributed to its labeling as an in vivo trans-synaptic tracer.

Prior to MEMRI, tract-tracing studies employed invasive techniques $(94,95)$, requiring tracers to be injected and animals sacrificed in order for these agents to be visualized. A major limitation of this methodology is that longitudinal studies cannot be carried out in the same animals. As MEMRI can be conducted multiple times, it has contributed to the in vivo temporal assessment of connectivity and integrity of neuronal tracts in several animal models (i.e., from small rodents to non-human primates) $(13,26$, 28, 96).

The ability of manganese to be taken up via voltage-gated $\mathrm{Ca}^{2+}$ channels has not only been explored for non-invasive tract tracing but also to functionally assess the rate of neuronal transport. This latter plays a crucial role in the normal functioning of neurons. In fact, perturbations in axonal transport and its machinery have been associated with disease states, such as Alzheimer's disease, diabetes, as well as with normal aging (97-99). In contrast to $\mathrm{Mn}^{2+}$, large tracer molecules may not accurately represent the axonal transport in in vivo systems.

\section{Activity-Induced Manganese MRI}

The main concept underlying the use of MEMRI for the assessment of neuronal activity is the fact that activated brain regions have elevated $\mathrm{Ca}^{2+}$ influx through $\mathrm{Ca}^{2+}$ channels. As mentioned before, in the presence of extracellular $\mathrm{Mn}^{2+}$ active regions will have greater $\mathrm{Mn}^{2+}$ influx, since manganese competes with $\mathrm{Ca}^{2+}$ to enter the cells. Thus, the accumulation of $\mathrm{Mn}^{2+}$ is directly related to brain activation and may provide information about brain function. This approach, which has been named activityinduced manganese MRI (46), led to the development of a $\mathrm{Mn}^{2+}$-based fMRI technique. It differs from traditional methods, because it does not take into account information on hemodynamic fluctuations and deoxy-hemoglobin concentration. Hence, the activity-induced manganese-dependent contrast (AIM) MRI produces maps with better spatial localization than those produced by conventional fMRI (19).

A particular concern related to AIM MRI experiments is that the $\mathrm{Mn}^{2+}$ cannot efficiently penetrate the BBB. The CSF route is particularly slow for this purpose $(87,100)$ and the amount of $\mathrm{Mn}^{2+}$ entering the brain is minimal compared to cases where the $\mathrm{BBB}$ is disrupted. As a result, several AIM MRI studies have been performed in conjunction with $\mathrm{BBB}$ disruption. On the other hand, some studies showing activation of the auditory (22, $23)$ and visual pathways $(30,101)$ following auditory and visual stimulation, respectively, were performed in mice without $\mathrm{BBB}$ disruption.

An interesting aspect of AIM MRI is that, after BBB disruption and upon brain stimulation, $\mathrm{Mn}^{2+}$ accumulates in active regions at a short time scale. Once accumulated, $\mathrm{Mn}^{2+}$ does not leave these regions for several hours. This allows $\mathrm{Mn}^{2+}$ to be delivered outside the scanner, while the animal is being freely moving or carrying out behavioral tasks. When compared with conventional fMRI protocols, this represents a new horizon in terms of functional evaluation. One of its disadvantages, however, is the intrinsic temporal resolution of the technique, which prevents the assessment of rapid changes in activity, particularly tissue deactivation (102). Besides providing valuable information to answer physiological questions, AIM MRI was proven to be an important tool for the study of spatial BOLD signal changes in the cortex $(19,45,103,104)$. This is particularly important because BOLD is the MRI-based "gold standard" method for measuring brain activity in humans and several methodological questions still remain to be addressed.

\section{MEMRI: Recent Applications in Experimental Animal Models}

Over the last years, MEMRI has been extensively used in neurosciences. Studies using this technique have addressed neurophysiological and neuroanatomical problems in animal models of nociception $(105,106)$, neurodegeneration $(35,36,99,107-111)$, and psychiatric disorders (112). 


\section{Activity-Dependent Signaling}

In animals, MEMRI has been used to determine high versus low activation of brain areas after specific stimuli or in models of brain disease. One example is the sequence of activation of the hypothalamic paraventricular nucleus, supraoptic nucleus, and preoptic area, which are thought to be involved in central osmotic regulation after intracarotid injection of hypertonic $\mathrm{NaCl}$ (113). In another study, mice exposed to an odorant showed localized $\mathrm{T}_{1}$ MRI signal enhancements in the olfactory epithelium and bulb (25). MEMRI has also been shown to be effective for mapping the mouse auditory brainstem (22). Chronic tinnitus (the perception of sounds in the absence of acoustic stimulation) in rats was associated with elevated focal activity in the auditory brainstem (114). On the other hand, a reduction in $\mathrm{Mn}^{2+}$ uptake was demonstrated in the rodent visual cortex in depression-like states (sickness behavior) induced by interferon- $\alpha$ (IFN- $\alpha$ ), which was related to altered local functionality (112).

\section{Epilepsy}

At first sight, these results may suggest a positive correlation between MEMRI enhancement and cell activation. However, other factors, such as tissue edema, neurodegeneration, and cell density (8), may also determine signal changes, as shown in animal models of epilepsy. Several rodents and non-human primate models have been used to study cellular mechanisms that underlie temporal lobe epilepsy (TLE), including those following pilocarpine, kainic acid (115-121), and pentylenetetrazol injections (122). In these models, status epilepticus (SE) represents an acute phase, after which the animals enter the silent period that ends with the occurrence of spontaneous recurrent seizures (chronic phase).
The temporal sequence and the neuropathological alterations that characterize these chronic models resemble those observed in human TLE. In rodents, the acute phase of the kainic acid model is characterized by a poorly defined MEMRI signal in areas with high-cellular activity (i.e., hippocampus) $(107,108)$. A possible explanation for this finding is that the MEMRI signal may have been obscured by cell damage that occurs at this early phase, especially when SE lasts more than $30 \mathrm{~min}$. Similar results have been shown during the acute phase of the pilocarpine model (35, 109), even when SE lasted only from 5 to $30 \mathrm{~min}$ (Figure 1). A proposed mechanism to explain this finding is that reductions in MEMRI signal could be related to hippocampal cell edema rather than apoptotic cell death (35). Both edema and cell death have to be taken into account when one is planning to map active or inactive brain areas with MEMRI

As mentioned above, both the kainic acid and pilocarpine models exhibit spontaneous recurrent seizures in the chronic phase, which, as described in humans, are accompanied by hippocampal sclerosis and mossy fiber sprouting (MFS) $(115,116,123,124)$. MRI has been largely used to study the chronic phase of TLE, since it allows a non-invasive longitudinal follow up using different approaches. These include anatomical imaging for evaluating hippocampal and amygdala volumetric changes (110, 125-128) and relaxometry for estimating relaxation times changes in different brain areas (i.e., hippocampus, amygdala, piriform cortex, and/or thalamus) (127, 129-131). Longitudinal studies may also be used to evaluate changes in spectroscopy so that biochemical changes may be characterized. As an example, the hippocampi of lithium-pilocarpine-treated rats have reduced $N$-acetylaspartate (NAA) and choline (Cho) peaks, as well as an increase in lactate
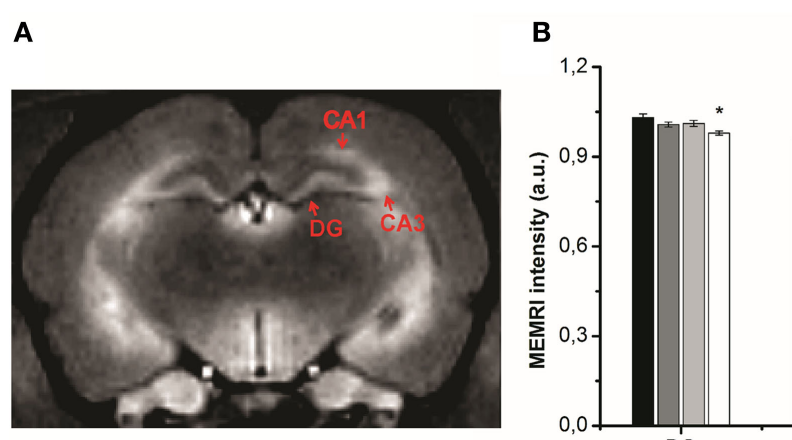

C

DG
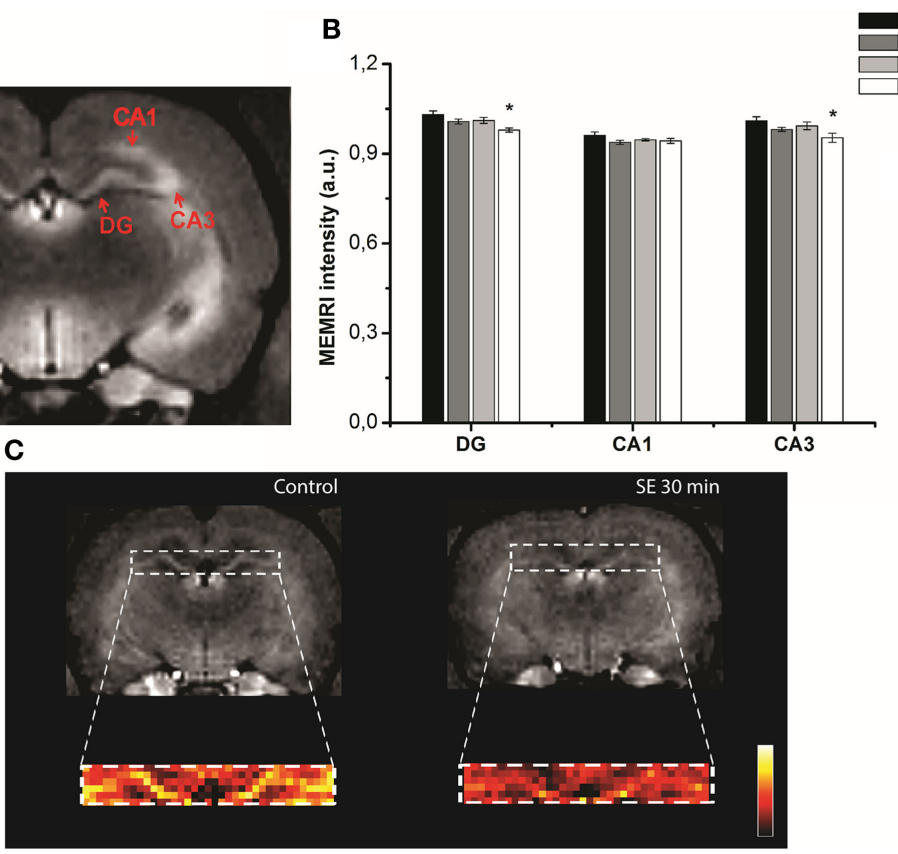

FIGURE 1 | Hippocampal MEMRI in pilocarpine injected animals, at different time points after status epilepticus (SE): 5 (SE 5 min), 15 (SE $\mathbf{1 5} \mathbf{~ m i n}$ ), and $\mathbf{3 0} \mathbf{~ m i n}$ (SE $\mathbf{3 0} \mathbf{~ m i n}$ ). $T_{1}$-weighted MEMRI images (A,C) and MEMRI data (B). Regions of interest (ROIs) drawn in hippocampal sub regions, including the DG (dentate gyrus), CA1 and CA3 (Cornu Ammonis), are represented in (A). The DG was enlarged and converted from gray into a colored scale in (C) to show differences between non-epileptic controls and the SE 30 group ( ${ }^{\star} P<0.01$ ). Reproduced with permission from Malheiros et al. (35). 

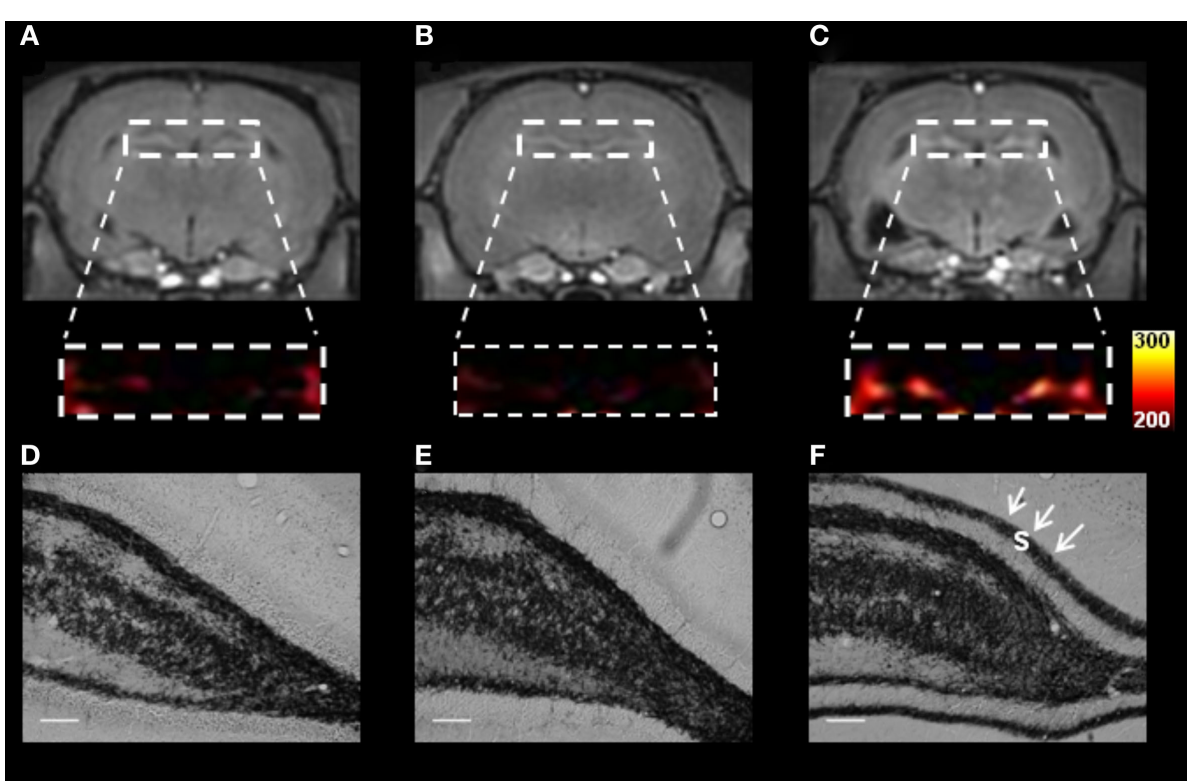

FIGURE 2 | $T_{1}$-weighted MEMRI (A-C) and representative photomicrographs (D-F) of pilocarpine-chronic epileptic rats (Pilo-treated) with no mossy fiber sprouting (MFS, left panel), Controls (middle panel), and Pilo-treated MFS-positive (right panel) animals. The dentate gyrus in MEMRI (A-C) was enlarged and converted from a gray into a colored scale. Pilo animals showed MFS in the supragranular layer (s, black arrowheads) and MEMRI hyperintensity in the DG. Similar abnormalities have not been detected in either epileptic animals with no MFS or controls. MRI data from the three groups were normalized to the muscle signal intensity to minimize possible signal differences. Scale bars $=50 \mu \mathrm{m}$. Reproduced with permission from Malheiros et al. (36) compared to non-epileptic controls (131). Besides these MRI approaches, MEMRI is used as a molecular imaging technique (35, $36,107-110)$. The focal and systemic administration of $\mathrm{MnCl}_{2}$ results in an increased hippocampal dentate gyrus MEMRI signal in kainic acid $(108,110)$ and pilocarpine-chronic epileptic rats (36). In these animals, signal changes correlates with aberrant MFS.

The relationship between MFS and MEMRI hyperintensity in pilocapine animals can be observed in Figure 2. Chronic pilocarpine rats that show aberrant MFS also show MEMRI hyperintensity. These signal changes have not been observed in pilocarpine animals in which MFS was suppressed by cycloheximide, suggesting that (1) MEMRI is able to detect hippocampal changes during the course of epileptogenesis and (2) a relationship exist between manganese enhancement and spontaneous seizure outcome (132). From the above-mentioned results, we conclude that MEMRI is a useful tool to follow important aspects related to neuronal plasticity, including those related to aberrant MFS and spontaneous recurrent seizures. Unfortunately, however, MEMRI may not be useful to study-activated areas during the acute phase of these models, as injury-related edema interferes in the signal.

\section{Pain}

In pain-related studies, MEMRI has been used to delineate functional connections between cortical and non-cortical areas; electrical stimulation of the left forepaw increased MEMRI signal in the contralateral anterior cingulate cortex, midcingulate cortex, retrosplenial cortex, ventral medial caudate-putamen, nucleus accumbens, and amygdala. Of those, signal changes in the retrosplenial cortex were attenuated by morphine injections (106). The efficacy of MEMRI to trace anatomical connections was indeed confirmed by $\mathrm{Mn}^{2+}$ transportation from the medial thalamus to the cingulate cortex and medial striatum, but not the motor cortex (106).

A recent study has shown reduced reactivity to thermal pain in the dorsal spinal cord following repeated amphetamine injections (133). The authors showed a temporal correlation between reduced pain sensitivity and increased MEMRI signals in the dorsal horn following repeated amphetamine administration. MEMRI has also been valuable in demonstrating the involvement of the hippocampus in the processing of pain during early development (105). As shown by different studies, noxious stimulation of newborn rats not only causes sex-specific long-term effects on the natural behavioral repertoire during adulthood $(35,134-136)$ but also dentate hippocampal cell activation.

In a rat model of pruritus, MEMRI has been used to investigate brain regions activated during itching. These were the parafascicular thalamic nucleus, superior/inferior colliculus, periaqueductal gray, cingulate cortex, amygdala, midbrain regions, lateral habenula, and hypothalamic areas (137). Gabapentin-treated itching rats decreased scratching behavior and had an attenuation of functional activity in the brain regions described above. Together, these results suggest that MEMRI hyperintensity is related to stimulus-induced activation of specific brain regions and that this techniques may be used as a strategy for understanding mechanisms of pain-related diseases.

\section{Axonal Transport}

Axonal transport is an essential physiological function. Its disruption severely interfere with neuronal viability and leads to distinct 
neurological disorders. As an example, axonal transport impairment occurs at the onset of optic neuritis in an experimental murine model of autoimmune encephalomyelitis (EAE). Using the MEMRI technique, it was demonstrated that $\mathrm{Mn}^{2+}$ accumulation and axonal transport were significantly decreased not only in these animals (138) but also in rTg4510 mice, which comprise a model of fronto-temporal dementia and parkinsonism (139). In a mouse model of Alzheimer's, axonal transport rates were shown to be reduced as soon as amyloid-beta $(A \beta)$ deposition begins. This reduction becomes even more pronounced after plaque formation (99). In this particular case, MEMRI showed that in vivo reduction in axonal transport can be detected prior to plaque formation.

\section{Mechanisms of Pathological $\mathrm{Mn}^{2+}$ Enhancement} Bearing in mind that $\mathrm{Mn}^{2+}$ enters neurons through $\mathrm{Ca}^{2+}$ channels and is transported along axonal transport systems, MEMRI has been used to trace the recovery of neuronal connectivity in experimental models of stroke (111). According to the authors, loss or dysfunction of neuronal connections, even outside the ischemic lesion, may explain the lasting impairment of function. Systemic $\mathrm{Mn}^{2+}$ injections in the acute phase of neonatal mild hypoxic-ischemia provide an enhanced MEMRI signal indicative of cortical gray matter lesion. This would be otherwise undetectable with conventional MRI techniques (140-142). In the late phase of the hypoxic-ischemia model, MEMRI signal was intense in the dorsolateral thalamus, hippocampus, and the remaining cortex of the injured hemisphere. This was co-localized with

\section{References}

1. Bernasconi A, Bernasconi N, Caramanos Z, Reutens DC, Andermann F, Dubeau F, et al. T2 relaxometry can lateralize mesial temporal lobe epilepsy in patients with normal MRI. Neuroimage (2000) 12:739-46. doi:10.1006/nimg. 2000.0724

2. Bernasconi N, Bernasconi A, Andermann E, Dubeau F, Feindel W, Reutens D. Entorhinal cortex in temporal lobe epilepsy. A quantitative MRI study. Neurology (1999) 52:1870-6. doi:10.1212/WNL.52.9.1870

3. Cendes F, Andermann F, Gloor P, Evans A, Jones-Gotman M, Watson $\mathrm{C}$, et al. MRI volumetric measurement of amygdala and hippocampus in temporal lobe epilepsy. Neurology (1993) 43:719-25. doi:10.1212/WNL.43. 4.719

4. Mamani JB, Malheiros JM, Cardoso EF, Tannus A, Silveira PH, Gamarra LF. In vivo magnetic resonance imaging tracking of C6 glioma cells labeled with superparamagnetic iron oxide nanoparticles. Einstein (Sao Paulo) (2012) 10(2):164-70. doi:10.1590/S1679-45082012000200009

5. Martins PC, Ayub-Guerrieri D, Martins-Bach AB, Onofre-Oliveira P, Malheiros JM, Tannus A, et al. Dmdmdx/Largemyd: a new mouse model of neuromuscular diseases useful for studying physiopathological mechanisms and testing therapies. Dis Model Mech (2013) 6(5):1167-74. doi:10.1242/dmm. 011700

6. Pelled G, Bergman H, Ben-Hur T, Goelman G. Manganese-enhanced MRI in a rat model of Parkinson's disease. J Magn Reson Imaging (2007) 26(4):863-70. doi:10.1002/jmri.21051

7. Jasanoff A. MRI contrast agents for functional molecular imaging of brain activity. Curr Opin Neurobiol (2007) 17(5):593-600. doi:10.1016/j.conb.2007. 11.002

8. Silva AC, Lee JH, Aoki I, Korestky AP. Manganese-enhanced magnetic resonance imaging (MEMRI): methodological and pratical considerations. NMR Biomed (2004) 17:532-43. doi:10.1002/nbm.945

9. Takeda A. Manganese action in brain function. Brain Res Brain Res Rev (2003) 41:79-87. doi:10.1016/S0165-0173(02)00234-5 reactive astrocytes, dying neurons, and activated microglia on histological analysis. MEMRI enhancement in this study had higher correlation with activated microglia (suggesting inflammatory process) than with dying cells (143).

\section{Conclusions}

Based on the above-mentioned studies, MEMRI may be considered as a powerful approach for in vivo studies to determine stimulus-dependent brain areas of activation, axonal transport, neuronal connectivity, and brain lesion in several experimental animal models. However, few challenges still have to be overcome so that researchers may take full advantage of all the benefits that this technique has to offer. Since dose-related toxicity is a major concern, there is a need to develop and further refine MRI pulse sequences in order to make them more sensitive to small changes in relaxation times. Also, it is important to develop better strategies to deliver the $\mathrm{Mn}^{2+}$ to the region of interest, reducing the risk of side effects after systemic $\mathrm{MnCl}_{2}$ injections. The combination of all of these aspects will likely allow MEMRI to be an even more powerful, versatile, and useful tool for modern neurosciences studies.

\section{Acknowledgments}

Financial Support: FAPESP 2009/53646-0; FAPESP CInAPCe Program 2005/56663-1; JM was supported by a FAPESP fellowship 07/52911-6.

10. Chuang $\mathrm{KH}$, Koretsky A. Improved neuronal tract tracing using manganese enhanced magnetic resonance imaging with fast T(1) mapping. Magn Reson Med (2006) 55:604-11. doi:10.1002/mrm.20797

11. Chuang KH, Koretsky AP. Accounting for nonspecific enhancement in neuronal tract tracing using manganese enhanced magnetic resonance imaging. Magn Reson Imaging (2009) 27:594-600. doi:10.1016/j.mri.2008.10.006

12. Van der Linden A, Van Meir V, Tindemans I, Verhoye M, Balthazart J. Applications of manganese-enhanced magnetic resonance imaging (MEMRI) to image brain plasticity in song birds. NMR Biomed (2004) 17(8):602-12. doi:10.1002/nbm.936

13. Van der Linden A, Verhoye M, Van Meir V, Tindemans I, Eens M, Absil $\mathrm{P}$, et al. In vivo manganese-enhanced magnetic resonance imaging reveals connections and functional properties of the songbird vocal control system. Neuroscience (2002) 112(2):467-74. doi:10.1016/S0306-4522(02)00070-2

14. Van Meir V, Verhoye M, Absil P, Eens M, Balthazart J, Van der Linden A. Differential effects of testosterone on neuronal populations and their connections in a sensorimotor brain nucleus controlling song production in songbirds: a manganese enhanced-magnetic resonance imaging study. Neuroimage (2004) 21(3):914-23. doi:10.1016/j.neuroimage.2003.10.007

15. Aoki I, Naruse S, Tanaka C. Manganese-enhanced magnetic resonance imaging (MEMRI) of brain activity and applications to early detection of brain ischemia. NMR Biomed (2004) 17(8):569-80. doi:10.1002/nbm.941

16. Natt O, Watanabe T, Boretius S, Radulovic J, Frahm J, Michaelis T. Highresolution 3D MRI of mouse brain reveals small cerebral structures in vivo. $J$ Neurosci Methods (2002) 120(2):203-9. doi:10.1016/S0165-0270(02)00211-X

17. Silva AC, Bock NA. Manganese-enhanced MRI: an exceptional tool in translational neuroimaging. Schizophr Bull (2008) 34(4):595-604. doi:10.1093/ schbul/sbn056

18. Watanabe T, Frahm J, Michaelis T. Functional mapping of neural pathways in rodent brain in vivo using manganese-enhanced three-dimensional magnetic resonance imaging. NMR Biomed (2004) 17:554-68. doi:10.1002/nbm.937

19. Duong TQ, Silva AC, Lee SP, Kim SG. Functional MRI of calcium-dependent synaptic activity: cross correlation with CBF and BOLD measurements. 
Magn Reson Med (2000) 43:383-92. doi:10.1002/(SICI)1522-2594(200003)43: 3<383::AID-MRM10>3.0.CO;2-Q

20. Lu H, Xi ZX, Gitajn L, Rea W, Yang Y, Stein EA. Cocaine-induced brain activation detected by dynamic manganese-enhanced magnetic resonance imaging (MEMRI). Proc Natl Acad Sci U S A (2007) 104:2489-94. doi:10.1073/ pnas.0606983104

21. Parkinson JR, Chaudhri OB, Bell JD. Imaging appetite-regulating pathways in the central nervous system using manganese-enhanced magnetic resonance imaging. Neuroendocrinology (2009) 89(2):121-30. doi:10.1159/000163751

22. Yu X, Wadghiri YZ, Sanes DH, Turnbull DH. In vivo auditory brain mapping in mice with Mn-enhanced MRI. Nat Neurosci (2005) 8:961-8. doi:10.1038/ nn1477

23. Yu X, Zou J, Babb JS, Johnson G, Sanes DH, Turnbull DH. Statistical mapping of sound-evoked activity in the mouse auditory midbrain using Mnenhanced MRI. Neuroimage (2008) 39(1):223-30. doi:10.1016/j.neuroimage. 2007.08.029

24. Murayama Y, Weber B, Saleem KS, Augath M, Logothetis NK. Tracing neural circuits in vivo with Mn-enhanced MRI. Magn Reson Imaging (2006) 24(4):349-58. doi:10.1016/j.mri.2005.12.031

25. Pautler RG, Koretsky AP. Tracing odor-induced activation in the olfactory bulbs of mice using manganese-enhanced magnetic resonance imaging. Neuroimage (2002) 16:441-8. doi:10.1006/nimg.2002.1075

26. Pautler RG, Mongeau R, Jacobs RE. In vivo trans-synaptic tract tracing from the murine striatum and amygdala utilizing manganese enhanced MRI (MEMRI). Magn Reson Med (2003) 50(1):33-9. doi:10.1002/mrm.10498

27. Pautler RG, Silva AC, Koretsky AP. In vivo neuronal tract tracing using manganese-enhanced magnetic resonance imaging. Magn Reson Med (1998) 40(5):740-8. doi:10.1002/mrm.1910400515

28. Saleem KS, Pauls JM, Augath M, Trinath T, Prause BA, Hashikawa T, et al. Magnetic resonance imaging of neuronal connections in the macaque monkey. Neuron (2002) 34(5):685-700. doi:10.1016/S0896-6273(02)00718-3

29. Watanabe T, Michaelis T, Frahm J. Mapping of retinal projections in the living rat using high-resolution 3D gradient-echo MRI with $\mathrm{Mn} 2+$-induced contrast. Magn Reson Med (2001) 46(3):424-9. doi:10.1002/mrm.1209

30. Bissig D, Berkowitz BA. Manganese-enhanced MRI of layer-specific activity in the visual cortex from awake and free-moving rats. Neuroimage (2009) 44(3):627-35. doi:10.1016/j.neuroimage.2008.10.013

31. de Sousa PL, de Souza SL, Silva AC, de Souza RE, de Castro RM. Manganeseenhanced magnetic resonance imaging (MEMRI) of rat brain after systemic administration of $\mathrm{MnCl} 2$ : changes in $\mathrm{T} 1$ relaxation times during postnatal development. J Magn Reson Imaging (2007) 25(1):32-8. doi:10.1002/jmri. 20792

32. Jackson SJ, Hussey R, Jansen MA, Merrifield GD, Marshall I, MacLullich A, et al. Manganese-enhanced magnetic resonance imaging (MEMRI) of rat brain after systemic administration of $\mathrm{MnCl}(2)$ : hippocampal signal enhancement without disruption of hippocampus-dependent behavior. Behav Brain Res (2011) 216(1):293-300. doi:10.1016/j.bbr.2010.08.007

33. Kuo YT, Herlihy AH, So PW, Bhakoo KK, Bell JD. In vivo measurements of T1 relaxation times in mouse brain associated with different modes of systemic administration of manganese chloride. J Magn Reson Imaging (2005) 21(4):334-9. doi:10.1002/jmri.20285

34. Lee JH, Silva AC, Merkle H, Korestky AP. Manganese-enhanced magnetic resonance imaging of mouse brain after systemic administration of $\mathrm{MnCl} 2$ : dose-dependent and temporal evolution of T1 contrast. Magn Reson Med (2005) 53:640-8. doi:10.1002/mrm.20368

35. Malheiros JM, Persike DS, Castro LU, Sanches TR, Andrade Lda C, Tannus A, et al. Reduced hippocampal manganese-enhanced MRI (MEMRI) signal during pilocarpine-induced status epilepticus: edema or apoptosis? Epilepsy Res (2014) 108(4):644-52. doi:10.1016/j.eplepsyres.2014.02.007

36. Malheiros JM, Polli RS, Paiva FF, Longo BM, Mello LE, Silva AC, et al. Manganese-enhanced magnetic resonance imaging detects mossy fiber sprouting in the pilocarpine model of epilepsy. Epilepsia (2012) 53(7):1225-32. doi:10.1111/j.1528-1167.2012.03521.x

37. Wadghiri YZ, Blind JA, Duan X, Moreno C, Yu X, Joyner AL, et al. Manganeseenhanced magnetic resonance imaging (MEMRI) of mouse brain development. NMR Biomed (2004) 17(8):613-9. doi:10.1002/nbm.932

38. Watanabe T, Natt $\mathrm{O}$, Boretius S, Frahm J, Michaelis T. In vivo 3D MRI staining of mouse brain after subcutaneous application of $\mathrm{MnCl}_{2}$. Magn Reson Med (2002) 48:852-9. doi:10.1002/mrm.10276
39. Watanabe T, Radulovic J, Boretius S, Frahm J, Michaelis T. Mapping of the habenulo-interpeduncular pathway in living mice using manganeseenhanced 3D MRI. Magn Reson Imaging (2006) 24(3):209-15. doi:10.1016/j. mri.2005.10.034

40. Gallez B, Demeure R, Baudelet C, Abdelouahab N, Beghein N, Jordan B, et al. Non invasive quantification of manganese deposits in the rat brain by local measurement of NMR proton T1 relaxation times. Neurotoxicology (2001) 22(3):387-92. doi:10.1016/S0161-813X(01)00020- 1

41. Liu CH, D’Arceuil HE, de Crespigny AJ. Direct CSF injection of $\mathrm{MnCl}(2)$ for dynamic manganese-enhanced MRI. Magn Reson Med (2004) 51(5):978-87. doi: $10.1002 / \mathrm{mrm} .20047$

42. Pautler RG. In vivo, trans-synaptic tract-tracing utilizing manganeseenhanced magnetic resonance imaging (MEMRI). NMR Biomed (2004) 17:595-601. doi:10.1002/nbm.942

43. Aoki I, Tanaka C, Takegami T, Ebisu T, Umeda M, Fukunaga M, et al. Dynamic activity-induced manganese-dependent contrast magnetic resonance imaging (DAIM MRI). Magn Reson Med (2002) 48:927-33. doi:10.1002/mrm. 10320

44. Koretsky AP. Is there a path beyond BOLD? Molecular imaging of brain function. Neuroimage (2012) 62(2):1208-15. doi:10.1016/j.neuroimage.2012. 02.076

45. Silva AC. Using manganese-enhanced MRI to understand BOLD. Neuroimage (2012) 62(2):1009-13. doi:10.1016/j.neuroimage.2012.01.008

46. Lin YJ, Koretsky AP. Manganese ions enhances T1-weighted MRI during brain activation: an approach to direct imaging of brain function. Magn Reson Med (1997) 38:378-88. doi:10.1002/mrm.1910380305

47. Barbeau A. Manganese and extrapyramidal disorders (a critical review and tribute to Dr. George C. Cotzias). Neurotoxicology (1984) 5(1):13-35.

48. Chandra SV, Shukla GS. Role of iron deficiency in inducing susceptibility to manganese toxicity. Arch Toxicol (1976) 35(4):319-23. doi:10.1007/ BF00570272

49. Crossgrove J, Zheng W. Manganese toxicity upon overexposure. NMR Biomed (2004) 17:544-53. doi:10.1002/nbm.931

50. Dobson AW, Erikson KM, Aschner M. Manganese neurotoxicity. Ann N Y Acad Sci (2004) 1012:115-28. doi:10.1196/annals.1306.009

51. Gorell JM, Johnson CC, Rybicki BA, Peterson EL, Kortsha GX, Brown GG, et al. Occupational exposure to manganese, cooper, lead, iron, mercury and zinc and the risk of Parkinson's disease. Neurotoxicology (1999) 20:239-47.

52. Bock NA, Paiva FF, Silva AC. Fractionated manganese-enhanced MRI. NMR Biomed (2008) 21(5):473-8. doi:10.1002/nbm.1211

53. Grunecker B, Kaltwasser SF, Peterse Y, Samann PG, Schmidt MV, Wotjak CT, et al. Fractionated manganese injections: effects on MRI contrast enhancement and physiological measures in C57BL/6 mice. NMR Biomed (2010) 23(8):913-21. doi:10.1002/nbm.1508

54. Grunecker B, Kaltwasser SF, Zappe AC, Bedenk BT, Bicker Y, Spoormaker VI, et al. Regional specificity of manganese accumulation and clearance in the mouse brain: implications for manganese-enhanced MRI. NMR Biomed (2013) 26(5):542-56. doi:10.1002/nbm.2891

55. Inoue T, Majid T, Pautler RG. Manganese enhanced MRI (MEMRI): neurophysiological applications. Rev Neurosci (2011) 22(6):675-94. doi:10.1515/ RNS.2011.048

56. Connick RE, Poulson RE. Effect of paramagnetic ions on the nuclear magnetic resonance of O-17 in water and the rate of elimination of water molecules from the 1st coordination sphere of cations. J Chem Phys (1959) 30:759-61. doi:10.1063/1.1730039

57. Lauffer RB. Magnetic resonance contrast media: principles and progress. Magn Reson $Q$ (1990) 6(2):65-84.

58. Sherry $\mathrm{AD}, \mathrm{Wu} \mathrm{Y}$. The importance of water exchange rates in the design of responsive agents for MRI. Curr Opin Chem Biol (2013) 17(2):167-74. doi:10.1016/j.cbpa.2012.12.012

59. Siriwardena-Mahanama BN, Allen MJ. Strategies for optimizing waterexchange rates of lanthanide-based contrast agents for magnetic resonance imaging. Molecules (2013) 18(8):9352-81. doi:10.3390/molecules18089352

60. Wuthrich K. NMR studies of structure and function of biological macromolecules (Nobel Lecture). J Biomol NMR (2003) 27(1):13-39. doi:10.1023/A: 1024756526171

61. Lauterbur PC. Image formation by induced local interactions: examples employing nuclear magnetic resonance. Nature (1973) 242:190-1. doi:10. $1038 / 242190 \mathrm{a} 0$ 
62. Tofts P. Quantitative MRI of the Brain: Measuring Changes Caused by Disease. Chichester: Wiley (2003). xvi p.

63. Kang YS, Gore JC. Studies of tissue NMR relaxation enhancement by manganese. Dose and time dependences. Invest Radiol (1984) 19(5):399-407. doi:10.1097/00004424-198409000-00012

64. Caravan P, Ellison JJ, McMurry TJ, Lauffer RB. Gadolinium(III) chelates as MRI contrast agents: structure, dynamics, and applications. Chem Rev (1999) 99(9):2293-352. doi:10.1021/cr980440x

65. Shokrollahi H. Contrast agents for MRI. Mater Sci Eng C Mater Biol Appl (2013) 33(8):4485-97. doi:10.1016/j.msec.2013.07.012

66. Friedman BJ, Freeland-Graves JH, Bales CW, Behmardi F, Shorey-Kutschke RL, Willis RA, et al. Manganese balance and clinical observations in young men fed a manganese-deficient diet. J Nutr (1987) 117(1):133-43.

67. Gonzalez-Reyes RE, Gutierrez-Alvarez AM, Moreno CB. Manganese and epilepsy: a systematic review of the literature. Brain Res Rev (2007) 53(2):332-6. doi:10.1016/j.brainresrev.2006.10.002

68. Wedler FC, Denman RB. Glutamine synthetase: the major Mn(II) enzyme in mammalian brain. Curr Top Cell Regul (1984) 24:153-69. doi:10.1016/ B978-0-12-152824-9.50021-6

69. Mena I, Marin O, Fuenzalida S, Cotzias GC. Chronic manganese poisoning: clinical picture and managanese turnover. Neurology (1967) 17(2):128-36. doi:10.1212/WNL.17.2.128

70. Racette BA, Antenor JA, McGee-Minnich L, Moerlein SM, Videen TO, Kotagal $\mathrm{V}$, et al. [18F]FDOPA PET and clinical features in parkinsonism due to manganism. Mov Disord (2005) 20(4):492-6. doi:10.1002/mds.20381

71. Wolf GL, Baum L. Cardiovascular toxicity and tissue proton T1 response to manganese injection in the dog and rabbit. AJR Am J Roentgenol (1983) 141(1):193-7. doi:10.2214/ajr.141.1.193

72. Canals S, Beyerlein M, Keller AL, Murayama Y, Logothetis NK. Magnetic resonance imaging of cortical connectivity in vivo. Neuroimage (2008) 40(2):458-72. doi:10.1016/j.neuroimage.2007.12.007

73. Shazeeb MS, Sotak CH. Dose dependence and temporal evolution of the T1 relaxation time and MRI contrast in the rat brain after subcutaneous injection of manganese chloride. Magn Reson Med (2012) 68(6):1955-62. doi:10.1002/ mrm. 24184

74. Sepulveda MR, Dresselaers T, Vangheluwe P, Everaerts W, Himmelreich U, Mata AM, et al. Evaluation of manganese uptake and toxicity in mouse brain during continuous $\mathrm{MnCl} 2$ administration using osmotic pumps. Contrast Media Mol Imaging (2012) 7(4):426-34. doi:10.1002/cmmi.1469

75. Bouilleret V, Cardamone L, Liu C, Koe AS, Fang K, Williams JP, et al. Confounding neurodegenerative effects of manganese for in vivo MR imaging in rat models of brain insults. J Magn Reson Imaging (2011) 34(4):774-84. doi:10.1002/jmri.22669

76. Daoust A, Saoudi Y, Brocard J, Collomb N, Batandier C, Bisbal M, et al. Impact of manganese on primary hippocampal neurons from rodents. Hippocampus (2014) 24(5):598-610. doi:10.1002/hipo.22252

77. Eschenko O, Canals S, Simanova I, Beyerlein M, Murayama Y, Logothetis NK. Mapping of functional brain activity in freely behaving rats during voluntary running using manganese-enhanced MRI: implication for longitudinal studies. Neuroimage (2010) 49(3):2544-55. doi:10.1016/j.neuroimage.2009.10.079

78. Eschenko O, Canals S, Simanova I, Logothetis NK. Behavioral, electrophysiological and histopathological consequences of systemic manganese administration in MEMRI. Magn Reson Imaging (2010) 28(8):1165-74. doi:10.1016/j. mri.2009.12.022

79. Bornhorst J, Wehe CA, Huwel S, Karst U, Galla HJ, Schwerdtle T. Impact of manganese on and transfer across blood-brain and blood-cerebrospinal fluid barrier in vitro. J Biol Chem (2012) 287(21):17140-51. doi:10.1074/jbc.M112. 344093

80. Aoki I, Wu YL, Silva AC, Lynch RM, Korestky AP. In vivo detection of neuroarchiteture in the rodent brain using manganese-enhanced MRI. Neuroimage (2004) 22:1046-59. doi:10.1016/j.neuroimage.2004.03.031

81. Murphy VA, Wadhwani KC, Smith QR, Rapoport SI. Saturable transport of manganese(II) across the rat blood-brain barrier. J Neurochem (1991) 57(3):948-54. doi:10.1111/j.1471-4159.1991.tb08242.x

82. Tjalve H, Henriksson J, Tallkvist J, Larsson BS, Lindquist NG. Uptake of manganese and cadmium from the nasal mucosa into the central nervous system via olfactory pathways in rats. Pharmacol Toxicol (1996) 79(6):347-56. doi:10.1111/j.1600-0773.1996.tb00021.x
83. Tjalve H, Mejare C, Borg-Neczak K. Uptake and transport of manganese in primary and secondary olfactory neurones in pike. Pharmacol Toxicol (1995) 77(1):23-31. doi:10.1111/j.1600-0773.1995.tb01909.x

84. Crossgrove JS, Allen DD, Bukaveckas BL, Rhineheimer SS, Yokel RA. Manganese distribution across the blood-brain barrier. I. Evidence for carriermediated influx of managanese citrate as well as manganese and manganese transferrin. Neurotoxicology (2003) 24(1):3-13. doi:10.1016/S0161-813X(02) 00089-X

85. Crossgrove JS, Yokel RA. Manganese distribution across the blood-brain barrier III. The divalent metal transporter-1 is not the major mechanism mediating brain manganese uptake. Neurotoxicology (2004) 25(3):451-60. doi:10.1016/j.neuro.2003.10.005

86. Crossgrove JS, Yokel RA. Manganese distribution across the blood-brain barrier. IV. Evidence for brain influx through store-operated calcium channels. Neurotoxicology (2005) 26(3):297-307. doi:10.1016/j.neuro.2004.09.004

87. Rabin O, Hegedus L, Bourre JM, Smith QR. Rapid brain uptake of manganese(II) across the blood-brain barrier. J Neurochem (1993) 61(2):509-17. doi:10.1111/j.1471-4159.1993.tb02153.x

88. Bock NA, Paiva FF, Nascimento GC, Newman JD, Silva AC. Cerebrospinal fluid to brain transport of manganese in a non-human primate revealed by MRI. Brain Res (2008) 1198:160-70. doi: 10.1016/j.brainres.2007. 12.065

89. Sloot WN, Gramsbergen JB. Axonal transport of manganese and its relevance to selective neurotoxicity in the rat basal ganglia. Brain Res (1994) 657(1-2):124-32. doi:10.1016/0006-8993(94)90959-8

90. Takeda A, Sawashita J, Okada S. Biological half-lives of zinc and manganese in rat brain. Brain Res (1995) 695(1):53-8. doi:10.1016/0006-8993(95) 00916-E

91. Chuang KH, Koretsky AP, Sotak CH. Temporal changes in the T1 and T2 relaxation rates (DeltaR1 and DeltaR2) in the rat brain are consistent with the tissue-clearance rates of elemental manganese. Magn Reson Med (2009) 61:1528-32. doi:10.1002/mrm.21962

92. Han JH, Chung YH, Park JD, Kim CY, Yang SO, Khang HS, et al. Recovery from welding-fume-exposure-induced MRI T1 signal intensities after cessation of welding-fume exposure in brains of cynomolgus monkeys. Inhal Toxicol (2008) 20(12):1075-83. doi:10.1080/08958370802116634

93. Hunter DR, Komai H, Haworth RA, Jackson MD, Berkoff HA. Comparison of $\mathrm{Ca} 2+, \mathrm{Sr} 2+$, and $\mathrm{Mn} 2+$ fluxes in mitochondria of the perfused rat heart. Circ Res (1980) 47(5):721-7. doi:10.1161/01.RES.47.5.721

94. Lanciego JL, Wouterlood FG. A half century of experimental neuroanatomical tracing. JChem Neuroanat (2011) 42(3):157-83. doi:10.1016/j.jchemneu.2011. 07.001

95. Naumann T, Hartig W, Frotscher M. Retrograde tracing with Fluoro-Gold: different methods of tracer detection at the ultrastructural level and neurodegenerative changes of back-filled neurons in long-term studies. J Neurosci Methods (2000) 103(1):11-21. doi:10.1016/S0165-0270(00)00292-2

96. Watanabe T, Radulovic J, Spiess J, Natt O, Boretius S, Frahm J, et al. In vivo 3D MRI staining of the mouse hippocampal system using intracerebral injection of $\mathrm{MnCl}$. Neuroimage (2004) 22(2):860-7. doi:10.1016/j.neuroimage.2004. 01.028

97. Cross DJ, Flexman JA, Anzai Y, Maravilla KR, Minoshima S. Age-related decrease in axonal transport measured by MR imaging in vivo. Neuroimage (2008) 39:915-26. doi:10.1016/j.neuroimage.2007.08.036

98. Sharma R, Buras E, Terashima T, Serrano F, Massaad CA, Hu L, et al. Hyperglycemia induces oxidative stress and impairs axonal transport rates in mice. PLoS One (2010) 5(10):e13463. doi:10.1371/journal.pone.0013463

99. Smith KD, Kallhoff V, Zheng H, Pautler RG. In vivo axonal transport rates decrease in a mouse model of Alzheimer's disease. Neuroimage (2007) 35(4):1401-8. doi:10.1016/j.neuroimage.2007.01.046

100. London RE, Toney G, Gabel SA, Funk A. Magnetic resonance imaging studies of the brains of anesthetized rats treated with manganese chloride. Brain Res Bull (1989) 23(3):229-35. doi:10.1016/0361-9230(89)90152-4

101. Berkowitz BA, Gradianu M, Bissig D, Kern TS, Roberts R. Retinal ion regulation in a mouse model of diabetic retinopathy: natural history and the effect of $\mathrm{Cu} / \mathrm{Zn}$ superoxide dismutase overexpression. Invest Ophthalmol Vis Sci (2009) 50(5):2351-8. doi:10.1167/iovs.08-2918

102. Lee JH, Koretsky AP. Manganese enhanced magnetic resonance imaging. Curr Pharm Biotechnol (2004) 5:529-37. doi:10.2174/1389201043376607 
103. Fa Z, Zhang P, Huang F, Li P, Zhang R, Xu R, et al. Activity-induced manganese-dependent functional MRI of the rat visual cortex following intranasal manganese chloride administration. Neurosci Lett (2010) 481(2):110-4. doi:10.1016/j.neulet.2010.06.063

104. Fa Z, Zhang P, Wu W, Wang Z, Huang F, Yang L, et al. Functional mapping of rat brain activation following rTMS using activity-induced manganese-dependent contrast. Neurol Res (2011) 33(6):563-71. doi:10.1179/ 1743132810Y.0000000009

105. Lima M, Malheiros J, Negrigo A, Tescarollo F, Medeiros M, Suchecki D, et al. Sex-related long-term behavioral and hippocampal cellular alterations after nociceptive stimulation throughout postnatal development in rats. Neuropharmacology (2014) 77:268-76. doi:10.1016/j.neuropharm.2013.10.007

106. Yang PF, Chen DY, Hu JW, Chen JH, Yen CT. Functional tracing of medial nociceptive pathways using activity-dependent manganese-enhanced MRI. Pain (2011) 152(1):194-203. doi:10.1016/j.pain.2010.10.027

107. Alvestad S, Goa PE, Qu H, Risa O, Brekken C, Sonnewald U, et al. In vivo mapping of temporospatial changes in manganese enhancement in rat brain during epileptogenesis. Neuroimage (2007) 38(1):57-66. doi:10.1016/j.neuroimage. 2007.07.027

108. Immonen RJ, Kharatishvili I, Sierra A, Einula C, Pitkanen A, Grohn OH. Manganese enhanced MRI detects mossy fiber sprouting rather than neurodegeneration, gliosis or seizure-activity in the epileptic rat hippocampus. Neuroimage (2008) 40(4):1718-30. doi:10.1016/j.neuroimage.2008.01.042

109. Malheiros JM, Longo BM, Tannus A, Covolan L. Manganese-enhanced magnetic resonance imaging in the acute phase of the pilocarpine-induced model of epilepsy. Einstein (Sao Paulo) (2012) 10(2):247-52. doi:10.1590/ S1679-45082012000200023

110. Nairismägi J, Pitkänen A, Kettunen MI, Kauppinen RA, Kubova H. Status epilepticus in 12-day-old rats leads to temporal lobe neurodegeneration and volume reduction: a histologic and MRI study. Epilepsia (2006) 47(3):479-88. doi:10.1111/j.1528-1167.2006.00455.x

111. van der Zijden JP, Wu O, van der Toorn A, Roeling TP, Bleys RL, Dijkhuizen RM. Changes in neuronal connectivity after stroke in rats as studied by serial manganese-enhanced MRI. Neuroimage (2007) 34(4):1650-7. doi:10.1016/j. neuroimage.2006.11.001

112. Daducci A, Tambalo S, Fiorini S, Osculati F, Teti M, Fabene PF, et al. Manganese-enhanced magnetic resonance imaging investigation of the interferon- $\alpha$ model of depression in rats. Magn Reson Imaging (2014) 32(5):529-34. doi:10.1016/j.mri.2014.02.006

113. Morita H, Ogino T, Seo Y, Fujiki N, Tanaka K, Takamata A, et al. Detection of hypothalamic activation by manganese ion contrasted $\mathrm{T}(1)$-weighted magnetic resonance imaging in rats. Neurosci Lett (2002) 326(2):101-4. doi:10. 1016/S0304-3940(02)00330-0

114. Brozoski TJ, Ciobanu L, Bauer CA. Central neural activity in rats with tinnitus evaluated with manganese-enhanced magnetic resonance imaging (MEMRI). Hear Res (2007) 228(1-2):168-79. doi:10.1016/j.heares.2007.02.003

115. Ben-Ari Y. Limbic seizure and brain damage prouced by kainic acid: mechanisms and relevance to human temporal lobe epilepsy. Neuroscience (1985) 14(2):375-403. doi:10.1016/0306-4522(85)90299-4

116. Cavalheiro EA, Riche DA, Le gal La Salle G. Long-term effects of intrahippocampal kainic acid injection in rats: a method for inducing spontaneous recurrent seizures. Electroencephalogr Clin Neurophysiol (1982) 53:581-9. doi:10.1016/0013-4694(82)90134-1

117. Leite JP, Bortolotto ZA, Cavalheiro EA. Spontaneous recurrent seizures in rats: an experimental model of partial epilepsy. Neurosci Biobehav Rev (1990) 14:511-7. doi:10.1016/S0149-7634(05)80076-4

118. Mello LE, Cavalheiro EA, Tan AM, Kupfer WR, Pretorius JK, Babb TL, et al. Circuit mechanisms of seizures in the pilocarpine model of chronic epilepsy: cell loss and mossy fiber sprouting. Epilepsia (1993) 34:985-95. doi:10.1111/j. 1528-1157.1993.tb02123.x

119. Perez-Mendes P, Blanco MM, Calcagnotto ME, Cinini SM, Bachiega J, Papoti $\mathrm{D}$, et al. Modeling epileptogenesis and temporal lobe epilepsy in a nonhuman primate. Epilepsy Res (2011) 96(1-2):45-57. doi:10.1016/j.eplepsyres. 2011.04.015

120. Turski L, Ikonomidou C, Turski WA, Bortolotto ZA, Cavalheiro EA. Cholinergic mechanisms and epileptogenesis. The seizures induced by pilocarpine: a novel experimental model of intractable epilepsy. Synapse (1989) 3:154-71. doi:10.1002/syn.890030207

121. Turski WA, Cavalheiro EA, Bortolotto ZA, Mello LM, Schwarz M, Turski L. Seizures produced by pilocarpine in mice: a behavioral, electroencephalographic and morphological analysis. Brain Res (1984) 321:237-53. doi:10.1016/0006-8993(84)90177-X

122. Bachiega JC, Blanco MM, Perez-Mendes P, Cinini SM, Covolan L, Mello LE. Behavioral characterization of pentylenetetrazol-induced seizures in the marmoset. Epilepsy Behav (2008) 13(1):70-6. doi:10.1016/j.yebeh.2008. 02.010

123. Covolan L, Mello LE. Assessment of the progressive nature of cell damage in the pilocarpine model of epilepsy. Braz J Med Biol Res (2006) 39(7):915-24. doi:10.1590/S0100-879X2006000700010

124. Mello LE, Covolan L. Spontaneous seizures preferentially injure interneurons in the pilocarpine model of chronic spontaneous seizures. Epilepsy Res (1996) 26(1):123-9. doi:10.1016/S0920-1211(96)00048-4

125. Bouilleret V, Nehlig A, Marescaux C, Namer IJ. Magnetic resonance imaging follow-up of progressive hippocampal changes in a mouse model of mesial temporal lobe epilepsy. Epilepsia (2000) 41:642-50. doi:10.1111/j.1528-1157. 2000.tb00223.x

126. Nairismägi J, Gröhn OHJ, Kettunen MI, Nissinen J, Kauppinen RA, Pitkänen A. Progression of brain damage after status epilepticus and its association with epileptogenesis: a quantitative MRI study in a rat model of temporal lobe epilepsy. Epilepsia (2004) 45(9):1024-34. doi:10.1111/j.0013-9580.2004. 08904.x

127. Polli RS, Malheiros JM, Dos Santos R, Hamani C, Longo BM, Tannus A, et al. Changes in hippocampal volume are correlated with cell loss but not with seizure frequency in two chronic models of temporal lobe epilepsy. Front Neurol (2014) 5:111. doi:10.3389/fneur.2014.00111

128. Wolf OT, Dyakin V, Patel A, Vadasz C, de Leon MJ, McEwen BS, et al. Volumetric structural magnetic resonance imaging (MRI) of the rat hippocampus following kainic acid (KA) treatment. Brain Res (2002) 934:87-96. doi:10. 1016/S0006-8993(02)02363-6

129. Dube C, Yu H, Nalcioglu O, Baram TZ. Serial MRI after experimental febrile seizures: altered T2 signal without neuronal death. Ann Neurol (2004) 56(5):709-14. doi:10.1002/ana.20266

130. Jupp B, Williams JP, Tesiram YA, Vosmansky M, O’Brien TJ. Hippocampal T2 signal change during amygdala kindling epileptogenesis. Epilepsia (2006) 47(1):41-6. doi:10.1111/j.1528-1167.2006.00368.x

131. Van Eijsden P, Notenboom RGE, Wu O, de Graan PNE, Van Nieuwenhuizen $\mathrm{O}$, Nicolay $\mathrm{K}$, et al. In vivo $1 \mathrm{H}$ magnetic resonance spectroscopy, T2-weighted and diffusion-weighted MRI during lithium-pilocarpine induced status epilepticus in the rat. Brain Res (2004) 1030:11-8. doi:10.1016/j. brainres.2004.09.025

132. Dedeurwaerdere S, Fang K, Chow M, Shen YT, Noordman I, van Raay L, et al Manganese-enhanced MRI reflects seizure outcome in a model for mesial temporal lobe epilepsy. Neuroimage (2013) 68:30-8. doi:10.1016/j.neuroimage. 2012.11.054

133. Lei BH, Chen JH, Yin HS. Repeated amphetamine treatment alters spinal magnetic resonance signals and pain sensitivity in mice. Neurosci Lett (2014) 583:70-5. doi:10.1016/j.neulet.2014.09.031

134. Leslie AT, Guinsburg R, Mello LE, Covolan L. Repetitive nociceptive stimuli in newborn rats do not alter the hippocampal neurogenesis. Pediatr Res (2008) 63(2):154-7. doi:10.1203/PDR.0b013e31815ef75d

135. Leslie ATFS, Akers K, Martinez-Canabal A, Mello L, Covolan L, Guinsburg R. Neonatal inflammatory pain increases hippocampal neurogenesis in rat pups. Neurosci Lett (2011) 501:78-82. doi:10.1016/j.neulet.2011.06.047

136. Negrigo A, Medeiros M, Guinsburg R, Covolan L. Long-term gender behavioral vulnerability after nociceptive neonatal formalin stimulation in rats. Neurosci Lett (2011) 490:196-9. doi:10.1016/j.neulet.2010.12.050

137. Jeong K-Y, Kang J-H. Investigation of the pruritus-induced functional activity in the rat brain using manganese-enhanced MRI. J Magn Reson Imaging (2014). doi:10.1002/jmri.24832

138. Lin TH, Kim JH, Perez-Torres C, Chiang CW, Trinkaus K, Cross AH, et al. Axonal transport rate decreased at the onset of optic neuritis in EAE mice. Neuroimage (2014) 14:244-53. doi:10.1016/j.neuroimage.2014.06. 009

139. Majid T, Ali YO, Venkitaramani DV, Jang MK, Lu HC, Pautler RG. In vivo axonal transport deficits in a mouse model of fronto-temporal dementia. Neuroimage Clin (2014) 31(4):711-7. doi:10.1016/j.nicl.2014.02.005

140. Yang J, Khong PL, Wang Y, Chu AC, Ho SL, Cheung PT, et al. Manganeseenhanced MRI detection of neurodegeneration in neonatal hypoxic-ischemic cerebral injury. Magn Reson Med (2008) 59(6):1329-39. doi:10.1002/mrm. 21484 
141. Yang J, Wu EX. Manganese-enhanced MRI detected the gray matter lesions in the late phase of mild hypoxic-ischemic injury in neonatal rat. Conf Proc IEEE Eng Med Biol Soc (2007) 2007:51-4. doi:10.1109/IEMBS.2007.4352220

142. Yang J, Wu EX. Detection of cortical gray matter lesion in the late phase of mild hypoxic-ischemic injury by manganese-enhanced MRI. Neuroimage (2008) 39(2):669-79. doi:10.1016/j.neuroimage.2007.09.009

143. Wideroe M, Olsen O, Pedersen TB, Goa PE, Kavelaars A, Heijnen C, et al. Manganese-enhanced magnetic resonance imaging of hypoxic-ischemic brain injury in the neonatal rat. Neuroimage (2009) 45(3):880-90. doi:10.1016/j. neuroimage.2008.12.007
Conflict of Interest Statement: The authors declare that the research was conducted in the absence of any commercial or financial relationships that could be construed as a potential conflict of interest.

Copyright (c) 2015 Malheiros, Paiva, Longo, Hamani and Covolan. This is an openaccess article distributed under the terms of the Creative Commons Attribution License (CC BY). The use, distribution or reproduction in other forums is permitted, provided the original author(s) or licensor are credited and that the original publication in this journal is cited, in accordance with accepted academic practice. No use, distribution or reproduction is permitted which does not comply with these terms. 